\title{
PRODUÇÃO CIENTÍFICA SOBRE PARADA \\ CARDIORRESPIRATÓRIA NOS PERIÓDICOS BRASILEIROS DE ENFERMAGEM: ESTUDO BIBLIOMÉTRICO
}

\section{SCIENTIFIC PRODUCTION ON CARDIORESPIRATORY ARREST IN BRAZILIAN NURSING JOURNALS: BIBLIOMETRIC STUDY}

\section{PRODUCCIÓN CIENTÍFICA SOBRE PARO CARDIORRESPIRATORIO EN REVISTAS BRASILEÑAS DE ENFERMERÍA: ESTUDIO BIBLIOMÉTRICO}

\author{
Nelson Miguel Galindo Neto ${ }^{1}$ \\ Kilse Uyara Sitônio Costa Martins ${ }^{2}$ \\ Priscylla Myrelle das Neves Silva ${ }^{3}$ \\ Rute Xavier Silva ${ }^{4}$ \\ Ana Carla Silva Alexandre \\ Guilherme Guarino de Moura Sá ${ }^{6}$
}

Como citar esse artigo: Galindo Neto NM, Martins KUSC, Silva PMN, Silva RX, Alexandre ACS, Sá GGM. Produção científica sobre parada cardiorrespiratória nos periódicos brasileiros de enfermagem: estudo bibliométrico. Rev baiana enferm. 2020;34:e36363.

Objetivo: analisar a produção científica sobre parada cardiorrespiratória nos periódicos brasileiros de enfermagem. Método: estudo bibliométrico realizado mediante acesso eletrônico aos websites das 14 revistas brasileiras de enfermagem, classificadas na Plataforma Sucupira, para análise dos artigos publicados entre 2010 e 2019. Resultados: foram analisados 18.266 artigos, dos quais 50 foram selecionados para integrar a amostra. Foi possível observar que $50 \%$ dos artigos foram publicados em periódicos de extrato Qualis A e 80\% das produções foram derivadas da Região Sudeste. Em relação ao tipo de estudo, 54\% foram descritivos e 64\% quantitativos. Quanto à temática mais investigada, $28 \%$ retrataram o conhecimento dos enfermeiros e $22 \%$ contemplaram o treinamento da enfermagem sobre parada cardiorrespiratória. Conclusão: a produção científica dos periódicos brasileiros demonstrou predominância de artigos publicados em periódico Qualis A, oriundos da Região Sudeste, do tipo descritivo, quantitativos, que investigaram predominantemente o conhecimento e o treinamento dos profissionais.

Descritores: Parada Cardiorrespiratória. Pesquisa em Enfermagem. Enfermagem. Bibliometria. Assistência de Enfermagem.

\footnotetext{
Enfermeiro. Doutor em Enfermagem. Professor do Instituto Federal de Educação, Ciência e Tecnologia de Pernambuco. Pesqueira, Pernambuco, Brasil. nelsongalindont@hotmail.com http://orcid.org/0000-0002-7003-165X.

Enfermeira. Pesquisadora independente. Pesqueira, Pernambuco, Brasil. http://orcid.org/0000-0003-0357-765X

Enfermeira. Pesquisadora independente. Pesqueira, Pernambuco, Brasil. http://orcid.org/0000-000 I-54| 9-840 I.

Estudante de Enfermagem. Instituto Federal de Educação, Ciência e Tecnologia de Pernambuco. Pesqueira, Pernambuco, Brasil. http://orcid.org/0000-000 I-5233-4553.

Enfermeira. Doutora em Ciências da Saúde. Professora do Instituto Federal de Educação, Ciência e Tecnologia de Pernambuco. Pesqueira, Pernambuco, Brasil. http:// orcid.org/0000-0002-5754-1778.

6 Enfermeiro. Mestre em Enfermagem, Professor do Instituto Federal de Educação, Ciência e Tecnologia de Pernambuco. Belo Jardim, Pernambuco, Brasil. http://orcid. org/0000-0003-3283-2656.
} 
Objective: to analyze the scientific production on cardiorespiratory arrest in Brazilian nursing journals. Method: bibliometric study carried out through electronic access to the websites of the 14 Brazilian nursing journals, classified in the Sucupira Platform, for analysis of articles published between 2010 and 2019. Results: 18,266 articles were analyzed, of which 50 were selected to integrate the sample. It was possible to observe that 50\% of the articles were published in Qualis A extract journals and $80 \%$ of the productions were derived from the Southeast Region. Regarding the type of study, 54\% were descriptive and 64\% quantitative. Regarding the most investigated theme, 28\% portrayed the knowledge of nurses and 22\% contemplated nursing training on cardiorespiratory arrest. Conclusion: the scientific production of Brazilian journals showed a predominance of articles published in Qualis A journals, from the Southeast Region, descriptive, quantitative, which predominantly investigated the knowledge and training of professionals.

Descriptors: Cardiorespiratory Arrest. Nursing Research. Nursing. Bibliometrics. Nursing Care.

Objetivo: analizar la producción científica sobre paro cardiorrespiratorio en revistas brasileñas de enfermería. Método: estudio bibliométrico realizado a través del acceso electrónico a los sitios de las 14 revistas brasileñas de enfermería, clasificadas en la Plataforma Sucupira, para el análisis de artículos publicados entre 2010 y 2019. Resultados: se analizaron 18.266 artículos, de los cuales 50 fueron seleccionados para integrar la muestra. Fue posible observar que el 50\% de los artículos fueron publicados en revistas de extracto Qualis A y el 80\% de las producciones se derivaron de la Región Sureste. En cuanto al tipo de estudio, el 54\% fueron descriptivos y 64\% cuantitativos. En cuanto al tema más investigado, el 28\% retrataron el conocimiento de las enfermeras y el 22\% contemplaban la formación de enfermería en el paro cardiorrespiratorio. Conclusión: la producción científica de revistas brasileñas mostró un predominio de artículos publicados en la revista Qualis A, de la Región Sureste, descriptivos, cuantitativos, que investigaron predominantemente el conocimiento y la formación de los profesionales.

Descriptores: Paro Cardiorrespiratorio. Investigación en Enfermería. Enfermería. Bibliometría. Atención de Enfermería.

\section{Introdução}

A Parada Cardiorrespiratória (PCR) constitui a condição de emergência na qual o indivíduo apresenta interrupção súbita do bombeamento cardíaco, sendo incompatível com a vida. Esta, no Brasil, acomete cerca de 200 mil pessoas por ano, metade delas em ambiente hospitalar ${ }^{(1)}$. É o agravo que possui a maior prioridade clínica, e para o qual a equipe de saúde necessita estar apta a reconhecer e prestar a assistência $\operatorname{adequada}^{(2)}$.

Dentre a equipe multiprofissional, o enfermeiro possui participação relevante na assistência à PCR, por atuar em todos os níveis de atenção à saúde e por participar efetivamente da Ressuscitação Cardiopulmonar (RCP), de forma que precisa estar qualificado e treinado para realizar a correta assistência ${ }^{(3)}$.

A qualificação e o treinamento perpassam pelo embasamento científico, que corrobora a prática Baseada em Evidência. Assim, denota-se a importância da produção científica acerca da PCR e destaca-se que a análise das produções científicas já realizadas é relevante, para que sejam conhecidas as lacunas existentes, que podem ser contempladas em estudos científicos futuros.

A divulgação das pesquisas ocorre por meio de periódicos científicos, que, no Brasil, cresceram em quantitativo nos últimos anos, nas variadas áreas do conhecimento ${ }^{(4)}$. Dentre os variados tipos de periódicos, aqueles que são vinculados a Programas de Pós-Graduação Stricto Sensu de Enfermagem tendem a divulgar as pesquisas realizadas por enfermeiros e são importantes para essa categoria profissional.

As pesquisas da Enfermagem têm contribuído com a conexão entre ciência e sociedade, construído parcerias, apresentado evidências científicas e aplicado-as na prática ${ }^{(5)}$. Diante da atuação transdisciplinar, a relevância das pesquisas da enfermagem é resultado da evolução da ciência da Enfermagem e da sua atuação clínica, centrada no paciente e família, para melhoria da saúde da população ${ }^{(6)}$. Nesse sentido, levanta-se 
o questionamento: Qual a caracterização das publicações acerca da parada cardiorrespiratória, nos periódicos brasileiros de enfermagem?

Diante do exposto, objetivou-se analisar a produção científica sobre a parada cardiorrespiratória nos periódicos brasileiros de enfermagem.

\section{Método}

Realizou-se estudo bibliométrico, que configura-se como técnica de análise das publicações, na qual, por meio de suas características, é possível compreender o cenário científico de determinado assunto e as lacunas que podem ser abordadas em estudos futuros ${ }^{(7)}$.

A coleta de dados foi efetuada entre dezembro de 2019 e janeiro de 2020, mediante acesso eletrônico aos websites das revistas brasileiras de enfermagem, cadastradas e classificadas na Plataforma Sucupira (pertencente ao Ministério da Educação, esta plataforma armazena os dados das produções científicas dos Programas de Pós-Graduação Strictu Sensu brasileiros, bem como divulga a lista dos periódicos científicos.

Mediante o acesso virtual à Plataforma Sucupira, obteve-se a lista completa dos periódicos e prosseguiu-se com o acesso aos websites de 14 revistas brasileiras de enfermagem. Nesse acesso, foi realizada consulta a cada volume e edição, com leitura de todos os títulos e resumos dos artigos publicados, para identificar os que tratassem da PCR.

Foram adotados os seguintes critérios de inclusão: ter sido publicado em periódico brasileiro de enfermagem, ter contemplado a Parada Cardiorrespiratória e ter sido publicado entre os anos de 2010 e 2019. Essa delimitação de tempo é justificada para assegurar um quantitativo adequado de estudos, uma vez que a inclusão elevada de pesquisas poderia impossibilitar a condução do método ou introduzir vieses na fase analítica. A análise dos estudos publicados nesse período permitiu analisar os indicadores bibliométricos da produção atual sobre o tema. O critério de exclusão adotado foi a não disponibilidade de acesso eletrônico.
Foram lidos os títulos e resumos de 18.266 artigos, dos quais 18.216 não abordavam Parada Cardiorrespiratória. Assim, a amostra do estudo foi de 50 produções. Para a extração dos dados dos artigos, foi utilizado instrumento adaptado de estudo bibliométrico ${ }^{(8)}$, que continha variáveis acerca do ano de publicação, nome dos periódicos em que foram publicados e seus respectivos Qualis/CAPES, tipo do estudo, nível de evidência (em sete níveis) ${ }^{(9)}$, abordagem (quantitativa ou qualitativa), subtema dos estudos publicados, público estudado, instituição de filiação e titulação dos autores, procedência geográfica dos estudos e descritores utilizados. Cabe destacar que o Qualis adotado para a caracterização dos artigos foi o mais recente, que se encontrava disponível na Plataforma Sucupira no momento de coleta e análise dos dados, correspondente ao quadriênio de 2013 a 2016.

A análise dos artigos seguiu as três leis bases do estudo bibliométrico: a Lei de Lotka aplica-se na relação entre o número de autores e o número de artigos publicados, relaciona-se à produtividade de autores e apresenta a ideia de que alguns pesquisadores publicam muito, enquanto muitos autores publicam pouco; Lei Bradford, refere-se aos periódicos cujos artigos foram publicados; e a Lei de Zipf, referente à contagem de frequência de palavras, foi contemplada devido a mensuração dos descritores/palavras-chave utilizadas nos estudos ${ }^{(7)}$.

As variáveis foram tabuladas no software Excel 2013 e analisadas pelo software R, mediante estatística descritiva. Por se tratar de pesquisa com informações de domínio público, não houve necessidade de apreciação por Comitê de Ética em Pesquisa (CEP).

\section{Resultados}

Em relação ao ano em que ocorreram as publicações, foram encontrados estudos publicados entre 2010 e 2019 e observaram-se maiores produções nos anos de 2015 e 2016 (Gráfico1). 
Gráfico 1 - Distribuição cronológica da publicação dos artigos. Pesqueira, Pernambuco, Brasil - 2020 $(\mathrm{N}=50)$

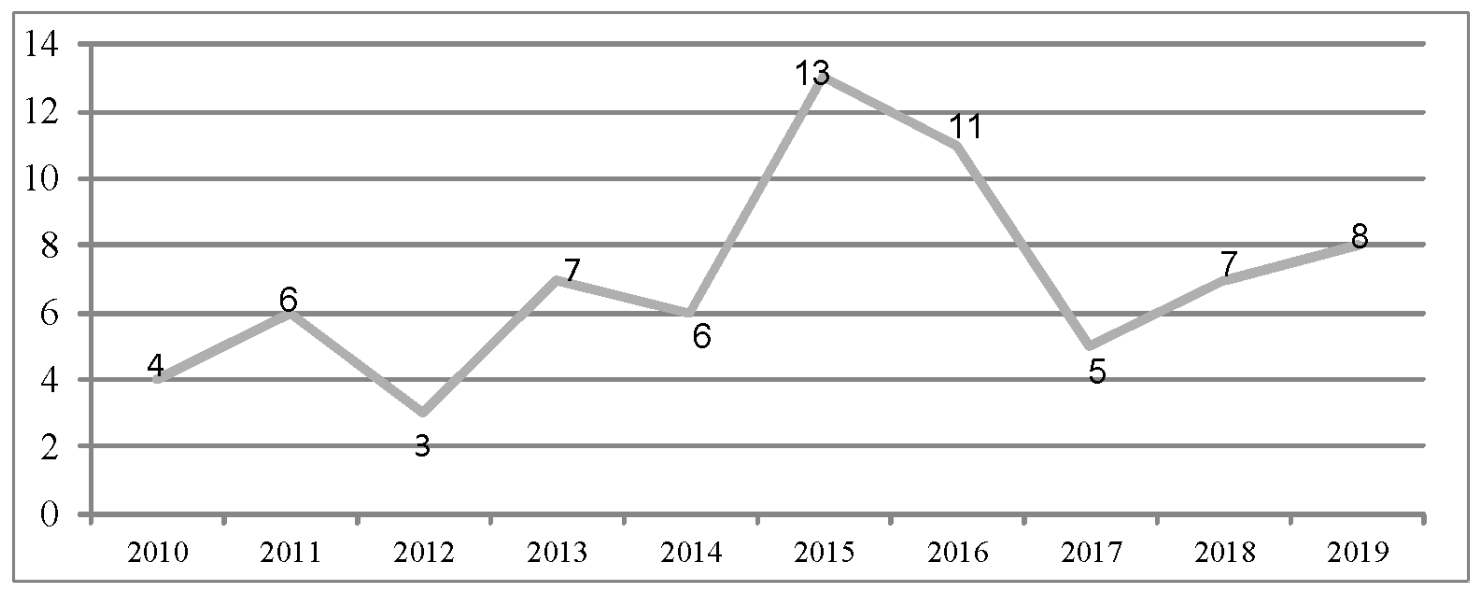

Fonte: Elaboração própria.

O número de publicações por Zona de Bradford foi de 16,66 artigos, visto que a lei orienta que cada zona deve conter $1 / 3$ do total das publicações encontradas. Foram estabelecidas três zonas de publicação, em ordem decrescente, nas quais, as revistas que estão nas zonas em menor quantidade possuem maior número de publicação de artigos.

A zona de núcleo foi composta pelas três revistas que possuíam mais de quatro publicações (Revista Latino-Americana de Enfermagem, Revista da Escola de Enfermagem da USP e Revista de Enfermagem UFPE Online). A zona dois foi composta pelas seis revistas que publicaram de dois a quatro artigos (Revista Brasileira de Enfermagem, Revista da Rede de Enfermagem do Nordeste, Revista Mineira de Enfermagem, Revista Eletrônica de Enfermagem, Revista Científica de Enfermagem e Revista Uningá). E a zona três, foi composta por cinco revistas que publicaram um artigo (ACTA Paulista de Enfermagem; Online Brazilian Journal Nursing; Cogitare; Revista Gaúcha de Enfermagem e Revista Saúde Santa Maria).

As 14 revistas nas quais os artigos foram publicados pertenciam a cinco extratos de Qualis (A1, A2, B1, B2 e B4). Observa-se que a maioria dos artigos (46\%) foi publicada em revistas de Qualis A. A Tabela 1 apresenta a classificação dos Qualis com a quantidade de artigos, por revista.

Tabela 1 - Distribuição dos artigos publicados, por revista. Pesqueira, Pernambuco, Brasil - 2020 $(\mathrm{N}=50)$

(continua)

\begin{tabular}{clc}
\hline Qualis & \multicolumn{1}{c}{ Revista } & n (\%) \\
\hline A1 & Revista Latino-Americana de Enfermagem & $11(22 \%)$ \\
A2 & ACTA Paulista de Enfermagem & $1(2 \%)$ \\
A2 & Revista Brasileira de Enfermagem & $3(6 \%)$ \\
A2 & Revista da Escola de Enfermagem da USP & $8(16 \%)$ \\
B1 & Online Brazilian Journal Nursing & $1(2 \%)$ \\
B1 & Revista da Rede de Enfermagem do Nordeste & $4(8 \%)$ \\
B1 & Revista Eletrônica de Enfermagem & $2(4 \%)$ \\
B1 & Revista Mineira de Enfermagem & $2(4 \%)$ \\
B1 & Revista Gaúcha de Enfermagem & $1(2 \%)$ \\
B1 & Cogitare & $1(2 \%)$ \\
B2 & Revista de Enfermagem UFPE Online & $10(20 \%)$
\end{tabular}


Tabela 1 - Distribuição dos artigos publicados, por revista. Pesqueira, Pernambuco, Brasil - 2020 $(\mathrm{N}=50)$

(conclusão)

\begin{tabular}{c|l|c}
\hline Qualis & \multicolumn{1}{c}{ Revista } & n (\%) \\
\hline B4 & Revista Científica de Enfermagem & $3(6 \%)$ \\
B4 & Revista Saúde (Santa Maria) & $1(2 \%)$ \\
B4 & Revista Uningá & $2(4 \%)$ \\
\hline
\end{tabular}

Fonte: Elaboração própria.

O tipo de estudo predominante foi o descritivo, presente em 27 artigos (54\%). Em seguida, houve nove artigos (18\%) de revisão integrativa. Quatro artigos (8\%) eram de relato de experiência, três (6\%) eram estudo metodológico, os estudos de caso controle, quase experimental e coorte estiveram presentes em dois artigos (4\%), cada. Um artigo (2\%) correspondeu à revisão sistemática.

Quanto aos níveis de evidência, foram identificados 26 artigos (52\%), no nível 6; 6 (12\%), no nível 4; 2 (4\%), no nível 3; e em 16 artigos (32\%) a classificação não se aplicou, por tratarem-se de revisões integrativas, estudo metodológico e relato de experiência.

A abordagem quantitativa esteve presente em 32 artigos (64\%), a qualitativa em 15 (30\%) e quantiqualitativa em 3 (6\%).

A Tabela 2 apresenta os subtemas abordados nos artigos analisados, nos quais observa-se predominância (28\%) de artigos sobre o conhecimento teórico dos profissionais de enfermagem.

Tabela 2 - Distribuição dos subtema identificados nos estudos publicados. Pesqueira, Pernambuco, Brasil - $2020(\mathrm{~N}=50)$

\begin{tabular}{lc}
\hline Subtema estudado & n (\%) \\
\hline Conhecimento da enfermagem sobre Parada Cardiorrespiratória & $14(28 \%)$ \\
Capacitação para enfermeiros sobre Parada Cardiorrespiratória & $11(22 \%)$ \\
Condutas de assistência na Parada Cardiorrespiratória & $7(14 \%)$ \\
Fatores associados à sobrevida na Ressuscitação Cardiopulmonar & $4(8 \%)$ \\
Caracterização dos pacientes acometidos por Parada Cardiorrespiratória & $4(8 \%)$ \\
Construção e validação de instrumentos usados na Ressuscitação & $3(6 \%)$ \\
Cardiopulmonar & $3(6 \%)$ \\
Uso de instrumentos que auxiliam na Ressuscitação Cardiopulmonar & $2(4 \%)$ \\
Conhecimentos de leigos sobre suporte básico de vida & $2(4 \%)$
\end{tabular}

Fonte: Elaboração própria.

No tocante ao público estudado, 23 artigos (46\%) realizaram investigação com enfermeiros; 17 (34\%), com pacientes; 5 (10\%), com técnicos em enfermagem; 4 (8\%), com estudantes de enfermagem; 2 (4\%), com condutores do Serviço de Atendimento Móvel de Urgência (SAMU); 2 (4\%) com pessoas leigas/não profissionais da saúde e 1 estudo (2\%) realizou investigação com estudantes surdos. Destaca-se que os valores citados extrapolam o quantitativo amostral de 50 artigos, uma vez que alguns artigos investigaram, concomitantemente, mais de um tipo de público.

Com base na Lei de Lotka, aplicou-se a relação do número de autores e identificou-se 134 autores presentes nos 50 artigos publicados. A maioria dos artigos (26\%) possuía seis autores. O número máximo de sete autores foi encontrado em quatro artigos (8\%), e o menor quantitativo de autores foi encontrado em um artigo (2\%), que possuía um autor. A Tabela 3 apresenta detalhadamente o quantitativo de autores nos artigos. 
Tabela 3 - Quantidade de autores nos artigos. Pesqueira, Pernambuco, Brasil - 2020 (N=50)

\begin{tabular}{lc}
\hline Quantidade de autores & n (\%) \\
\hline Um autor & $1(2 \%)$ \\
Dois autores & $8(16 \%)$ \\
Três autores & $10(20 \%)$ \\
Quatro autores & $9(18 \%)$ \\
Cinco autores & $5(10 \%)$ \\
Seis autores & $13(26 \%)$ \\
Sete autores & $4(8 \%)$ \\
\hline
\end{tabular}

Fonte: Elaboração própria.

Quanto à titulação dos 134 autores, 65 (48,50\%) eram doutores; 30 (22,38\%) eram mestres; 17 (12,68\%), graduados; 12 (8,95\%) eram acadêmicos e $10(7,46 \%)$, especialistas.

Em relação à instituição de filiação dos autores, foram identificadas 57 instituições, distribuídas em 14 estados nacionais. Em 17 artigos (34\%), os autores pertenciam à mesma instituição, enquanto em 33 (66\%), havia autores de distintas instituições. Em 15 artigos (30\%) havia
3 instituições nas quais os autores possuíam filiação; em 12 artigos (24\%), 2 instituições; e em 6 artigos (12\%), 4 ou mais instituições.

Acerca da distribuição geográfica, a Tabela 4 apresenta as localizações das instituições de filiação dos autores, por estado e região. Observa-se que o quantitativo apresentado na Tabela ultrapassa a amostra, uma vez que, dos 50 artigos, 9 (18\%) possuíam autores de mais de um estado.

Tabela 4 - Localizações geográficas das instituições de filiação dos autores, por estado e região. Pesqueira, Pernambuco, Brasil - 2020 (N=50)

\begin{tabular}{l|c}
\hline Região/Estado & n (\%) \\
\hline Sudeste & $30(60 \%)$ \\
São Paulo & $6(12 \%)$ \\
Minas Gerais & $3(6 \%)$ \\
Espirito Santo & $1(2 \%)$ \\
Rio de Janeiro & \\
Nordeste & $3(6 \%)$ \\
Pernambuco & $1(2 \%)$ \\
Ceará & $1(2 \%)$ \\
Piauí & $1(2 \%)$ \\
Rio Grande do Norte & \\
Centro-Oeste & $3(6 \%)$ \\
Brasília & $1(2 \%)$ \\
Mato Grosso & $1(2 \%)$ \\
Mato Grosso do Sul & \\
Sul & $3(6 \%)$ \\
Paraná & $1(2 \%)$ \\
Rio Grande do Sul & $1(2 \%)$ \\
Santa Catarina & \\
\hline
\end{tabular}

Fonte: Elaboração própria. 
Em 47 artigos (94\%) observou-se a presença de autores brasileiros; em dois artigos (4\%) a presença de autores da Espanha; e em um artigo (2\%), autores do Paraguai.

Após a aplicação da Lei de Zipf, foram encontrados 80 descritores. Destes, 28 apareceram cada um em 1 estudo, e 52 descritores estiveram presentes em mais de 2 estudos, cada. Os 5 descritores com maior frequência nos artigos foram: "Parada Cardíaca", presente em 38 artigos (76\%); "Ressuscitação cardiopulmonar", em 36 (72\%); "Enfermagem", em 12 artigos (24\%); "Serviços médicos de emergência", em 9 (18\%) e "Enfermagem em Emergência" em 8 artigos (16\%).

Baseado na aplicação da Lei de Zipf, foi possível construir uma lista das palavras-chaves cadastradas nas dissertações e teses. Foram encontradas 3.745 formas (palavras-chave), com 1.329 ocorrências. As palavras-chave com maior frequência foram "Cuidado Pré-natal" com 197 (14,9\%) ocorrências, seguida por "Gestante" com 134 (10\%), "Gravidez" com 125 (9,4\%), "Gestação" com 96 (7,2\%), "Pré-natal" com 93 (7\%), e "Enfermagem" com 76 (5,7\%). As demais, 608 (45,8\%) palavras contemplaram agravos à saúde, como sífilis, diabetes mellitus gestacional, pré-eclâmpsia, obesidade, depressão, ansiedade, anemia, zika vírus e toxoplasmose.

\section{Discussão}

O aumento de pesquisas e publicações na Enfermagem é resposta da crescente expansão científica brasileira. Tal crescimento foi impulsionado pelo aumento dos Programas de Pós-Graduação em Enfermagem, cuja oferta teve aumento de $42 \%$ dos cursos de doutorado e de $29 \%$ dos cursos de mestrado acadêmico, com consequente elevação da produção científica, que quase dobrou no triênio 2010-2012 ${ }^{(10)}$.

O crescimento de oferta de doutorados pode justificar o fato da maioria dos autores dos artigos serem doutores. O doutorado consiste em um curso de Pós-Graduação Strictu Sensu, focado em formar pesquisadores ${ }^{(11)}$. Assim, o aumento de tais cursos, com perfil científico, contribui com a formação de maior número de doutores, que possuem maior tendência para realizar e publicar pesquisas.

Observou-se que as publicações referentes à PCR, nos periódicos brasileiros de enfermagem, não ocorreram de forma regular no decorrer dos anos, com maior número de publicações no ano de 2015. Essa irregularidade não foi encontrada em estudo que investigou artigos acerca da prática reflexiva na enfermagem da Coreia ${ }^{(12)}$. Esses achados apontam a necessidade de realização de mais estudos acerca das temáticas com poucas publicações e de quantidade irregular no decorrer dos anos, para contribuir com o estado da arte e a prática baseada em evidência da Enfermagem brasileira.

Em relação aos periódicos nos quais os artigos foram publicados, observou-se predominância de publicações em revistas classificadas pela Coordenação de Aperfeiçoamento de Pessoal de Nível Superior (CAPES) com Qualis A. Uma vez que o Qualis consiste na classificação dos periódicos científicos, com base em fatores como periodicidade, internacionalização e fator de impacto ${ }^{(13)}$, é relevante que os artigos sobre PCR encontrem-se publicados em revistas de maior Qualis, para assim possuírem maior amplitude de divulgação científica.

No tocante ao tipo de estudo e nível de evidência, a maioria dos artigos foi do tipo descritivo, com nível de evidência 6. Tal resultado é semelhante ao encontrado em revisão de escopo sobre a retenção de enfermeiros, oriunda do Reino Unido, cujos resultados apontam predominância de artigos descritivos ${ }^{(14)}$. Apesar da contribuição e relevância dos estudos descritivos para incorporar os resultados de pesquisa na prática clínica, é necessário que ocorra investimento financeiro e científico em estudos com maior nível de evidência (quase experimentais, experimentais e/ou revisões sistemáticas com meta-análise), que alicercem cientificamente as condutas da enfermagem, com base nas particularidades brasileiras.

No que se refere à abordagem metodológica, houve predomínio de estudos quantitativos. Tal achado converge ao encontrado em estudo bibliométrico cujos resultados mostraram que a 
maioria das dissertações e teses da enfermagem em Portugal, sobre cuidados paliativos, também eram quantitativas $^{(15)}$. Diante disso, aponta-se a importância de investigação quantitativa sobre a PCR, para que parâmetros estatísticos viabilizem a inferência de informações, como frequências, comparações e associações entre variáveis. Entretanto, diante dos aspectos subjetivos envolvidos na assistência à PCR, por parte dos diversos atores envolvidos no processo (vítima, familiares, testemunhas, profissionais), destaca-se também a relevância de realização de pesquisas qualitativas.

Acerca da população e subtemas investigados nos artigos, houve predominância de estudos sobre conhecimento e treinamentos, realizados com os profissionais. Estudo bibliométrico, realizado nas dissertações e teses da enfermagem sobre o Serviço de Atendimento Móvel de Urgência, também encontrou predomínio de estudos com os profissionais ${ }^{(16)}$. É relevante que os aspectos profissionais, como qualificação, conhecimento e saúde ocupacional, sejam alvo de pesquisas, pois a integralidade do profissional é fator decisivo na qualidade do atendimento e, logo, na sobrevida e gravidade de sequelas. Ainda assim, é relevante que as pesquisas sobre PCR, contemplem os demais atores envolvidos no processo de promoção, prevenção, diagnóstico, tratamento e reabilitação das vítimas de PCR.

Ademais, pesquisas sobre o conhecimento e o treinamento são importantes, diante da necessidade de qualificação profissional para atendimento à PCR. Entretanto, é pertinente que os estudos investiguem aspectos importantes para a sobrevida, referentes aos procedimentos, cuidados de enfermagem e desfecho dos pacientes, além da educação em saúde voltada à população leiga.

Quanto à filiação institucional dos autores, observou-se que a maioria dos artigos possuía autores de distintas instituições, o que aponta para a produção científica realizada em rede de colaboração interinstitucional. Esse fato possui relação com a crescente consolidação de grupos de pesquisas em enfermagem, em ascensão desde 2006, nas diferentes subáreas da saúde ${ }^{(17)}$, o que possibilita a interação entre pesquisadores e, logo, o estabelecimento de parcerias para produção científica.

O maior número de publicações acerca da PCR ocorreu na Região Sudeste. Tal realidade foi encontrada também em estudo que analisou as dissertações e teses de enfermeiros sobre a Unidade de Terapia Intensiva (UTI) ${ }^{(18)}$. A predominância do sudeste pode ser explicada pelo seu pioneirismo, na concentração de instituições de ensino superior, com programas de pós-graduação e pesquisadores. Nessa vertente, ao considerar a pluralidade Brasil, urge a necessidade de estudos que contemplem as diversas regiões do país, para que os aspectos específicos de cada uma delas possa ser alvo de investigação científica.

Os descritores encontrados nos artigos, em sua maioria, apontaram para o objeto do estudo e versaram sobre a parada cardiorrespiratória. Tal achado diverge do encontrado em estudo sobre a Teoria Fundamentada nos Dados nos artigos de Enfermagem, cujos resultados mostraram predominância do descritor "Enfermagem", de forma a fazer menção/destaque não ao objeto dos artigos, mas à profissão ${ }^{(19)}$. Nesse contexto, aponta-se a importância da criteriosa escolha dos descritores, para proporcionar melhor divulgação dos achados dos estudos, pois o descritor principal facilita a localização das publicações nos periódicos e bases de dados. Assim, é imperativo que haja equilíbrio na quantidade de descritores que fazem alusão à profissão com descritores que evocam o objeto estudado ou a especialidade da enfermagem.

Este estudo apresenta como limitação os artigos analisados serem oriundos de periódicos brasileiros específicos de enfermagem, portanto, os resultados encontrados podem divergir da realidade dos estudos publicados em revistas da saúde pertencentes a outras categorias profissionais ou em periódicos internacionais.

Este estudo contribui para a análise da caracterização da produção científica disponibilizada em periódicos de enfermagem do Brasil sobre a temática, e possibilita que os enfermeiros identifiquem as lacunas existentes e possam realizar 
e replicar pesquisas acerca da parada cardiorrespiratória. Além disso, este estudo possibilita o fortalecimento da discussão sobre o tema no meio acadêmico e viabiliza a busca por parcerias interinstitucionais, multiprofissionais e interdisciplinares.

\section{Conclusão}

Este estudo apresentou tendências e lacunas na pesquisa de enfermagem relacionada à parada cardiorrespiratória. Os indicadores bibliométricos analisados constataram a predominância de artigos publicados em periódico Qualis A, oriundos da Região Sudeste, do tipo descritivo, quantitativos, que investigaram predominantemente o conhecimento e o treinamento dos profissionais.

Aponta-se a necessidade de estudos futuros contemplarem aspectos subjetivos existentes na PCR, mediante pesquisas qualitativas. Ademais, são necessários estudos com maior nível de evidência (quase experimentais, experimentais e/ou revisões sistemáticas com meta-análise). Quanto à população investigada, faz-se necessário que mais estudos possuam como alvo da

\section{Referências}

1. Bernoche C, Timerman S, Polastri TF, Giannetti NS, Siqueira AWS, Piscopo A, et al. Atualização da Diretriz de Ressuscitação Cardiopulmonar e Cuidados Cardiovasculares de Emergência da Sociedade Brasileira de Cardiologia - 2019. Arq Bras Cardiol. 2019; 113(3):449-663. DOI: 10.5935/ abc. 20190203

2. Panchal AR, Berg KM, Cabañas JG, Kurz MC, Link MS, Rios MD, et al. 2019 American Heart Association Focused Update on Systems of Care: Dispatcher-Assisted Cardiopulmonary Resuscitation and Cardiac Arrest Centers. Circulation. 2019;140:e895-e903. DOI: 10.1161/CIR.0000000000000733

3. Pettersen TR, Martensson J, Axelsson A, Jørgensen M, Strömberg A, Thompson DR, et al. European cardiovascular nurses' and allied professionals' knowledge and practical skills regarding cardiopulmonary resuscitation. investigação os diversos públicos envolvidos na assistência à PCR, como a vítima, familiares, testemunhas e equipe multiprofissional. Destaca-se também a relevância de realização de pesquisas que contemplem procedimentos, cuidados de enfermagem, desfecho dos pacientes e a educação em saúde voltada à população leiga.

\section{Colaborações:}

1 - concepção, projeto, análise e interpretação dos dados: Nelson Miguel Galindo Neto, Kilse Uyara Sitônio Costa Martins, Priscylla Myrelle das Neves Silva e Rute Xavier Silva;

2 - redação do artigo e revisão crítica relevante do conteúdo intelectual: Nelson Miguel Galindo Neto, Kilse Uyara Sitônio Costa Martins, Priscylla Myrelle das Neves Silva, Rute Xavier Silva, Ana Carla Silva Alexandre e Guilherme Guarino de Moura Sá;

3 - aprovação final da versão a ser publicada: Nelson Miguel Galindo Neto, Kilse Uyara Sitônio Costa Martins, Priscylla Myrelle das Neves Silva, Rute Xavier Silva, Ana Carla Silva Alexandre e Guilherme Guarino de Moura Sá.

Europ J Cardiov Nurs. 2017;17(4):336-44. DOI: $10.1177 / 1474515117745298$

4. Crossetti MGO. In evidence: internationalization and visibility of cientific communication in nursing. Rev Enferm UFSM [Internet]. 2015[cited 2019 Dec 9];5(3):2. Available from: https://periodicos.ufsm. br/reufsm/article/download/19746/pdf

5. Thompson MR, Barcott DS. The Role of the Nurse Scientist as a Knowledge Broker. J Nurs Schorlaship. 2019;51(1):26-39. DOI: 10.1111/jnu.12439

6. Cohn EG, McCloskey DJ, Kovner CT, Schiffman $\mathrm{R}$, Mitchell PH. Connecting translational nurse scientists across the nationâ€"the nurse scientisttranslational research interest group. OJIN [Internet]. 2018[cited 2019 Dec 9];23(2):1. Available from: https://nyuscholars.nyu.edu/en/publications/ connecting-translational-nurse-scientists-acrossthe-nation $\% \mathrm{C} 3 \% \mathrm{~A} 2$ the-n

7. Salvador GP. Una nueva perspectiva teórica de la bibliometria basada em su dimensión 
histórica y sus referentes temporales. Investig bibl. 2016;30(70):11-6. DOI: https://doi.org/10.1016/j. ibbai.2016.10.001

8. Santos MAB, Sá GGM, Caetano JA, Costa AB, Muniz MLC, Galindo Neto NM. Dissertações e teses da enfermagem brasileira acerca da unidade de terapia intensiva. Rev Rene [Internet]. 2017 [cited 2019 Dec 14];18(4):521-7. Available from: http://periodicos.ufc.br/rene/article/view/20256

9. Melnyk BM, Fineout-Overholt E. Makingthe case for evidence-based practice. In: Melnyk BM, Fineout-Overholt E. Evidence-based practice in nursing \& healthcare: a guide to best practice. Philadelphia (US): Lippincott Williams \& Wilkins; 2005. p. 3-24.

10. Coordenação de Aperfeiçoamento de Pessoal de Nível Superior. Relatório de avaliação 2010-2012. Trienal 2013 [Internet]. Brasília (DF); 2013 [cited 2019 Dec 2]. Available from: https://docs.google. $\mathrm{com} /$ viewer?a=v\&pid=sites\&srcid=Y2FwZXMuZ29 2LmJyfHRyaWVuYWwtMjAxM3xneDo1MDYyMTg 4ZmYxYTk4MWUw

11. Bates M, Hargreaves J, Perron S, Denny J. Support for nurses earning doctoral degrees. Nurs Manag. 2019;50(6):7-10. DOI: 10.1097/01. NUMA.0000558480.62072.24

12. Lee M, Jang KS. Reflection-related Research in Korean Nursing: A Literature Review. J Korean Acad Nurs Adm [Internet]. 2019 [cited 2020 Jan 6];25(2):83-96. Available from: https://www. koreamed.org/SearchBasic.php?RID=2442589

13. Souza AR, Souza G, Bruel AL. Ferraz MA. Qualis: a construção de um indicador para os periódicos na área da Educação. Práxis Educativa [Internet]. 2018 [cited 2020 Jan 5]; 13(1):219-31. DOI: https:// doi.org/10.5212/PraxEduc.v.13i1.0013
14. Collard SS, Scammell J, Tee S. Closing the gap on nurse retention: A scoping review of implications for undergraduate education. Nurse Educ Today. 2020;84(1):104253. DOI: https://doi. org/10.1016/j.nedt.2019.104253

15. Ferreira MAL, Pereira AMNAP, Martins JCA, Barbieri-Figueiredo MC. Palliative care and nursing in dissertations and theses in Portugal: a bibliometric study. Rev esc enferm USP. 2016;50(2):317-23. https://doi.org/10.1590/ S0080-623420160000200019

16. Agra MAC, Freitas TCS, Caetano JÁ, Alexandre ACS, Sá GGM, Galindo Neto NM. Dissertações e teses da enfermagem acerca do serviço de atendimento móvel de urgência: estudo bibliométrico. Texto Contexto Enferm. 2018;27(1):e3500016. DOI: https://doi.org/10.1590/0104-07072018003500016

17. Erdmann AL, Peiter CC, Lanzoni, GMM. Grupos de pesquisa em enfermagem no Brasil: comparação dos perfis de 2006 e 2016. Rev Gaúcha Enferm. 2017;38(2):e69051. DOI: http://dx.doi. org/10.1590/1983-1447.2017.02.69051

18. Lima Neto AV, Gomes ATL, Saraiva COPO, Medeiros SG, Barbosa ML, Santos VEP. Contexto da unidade de terapia intensiva: análise da produção científica da enfermagem. Rev Enferm UFSM. 2020;10e:1-16. DOI: https://doi.org/10.5902/2179769234846

19. Peiter CC, Santos JLG, Kahl C, Copelli FHS, Cunha KS, Lacerda MR. Teoria Fundamentada nos Dados: utilização em artigos de revistas brasileiras de enfermagem com Qualis A. Texto Contexto Enferm. 2020;29:e20180177. DOI: http://dx.doi. org/10.1590/1980-265X-TCE-2018-0177

Recebido: 14 de abril de 2020

Aprovado: 10 de junho de 2020

Publicado: 2 de setembro de 2020

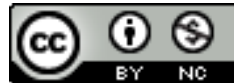

A Revista Baiana de Enfermagem utiliza a Licença Creative Commons - Atribuição-NãoComercial 4.0 Internacional. https://creativecommons.org/licenses/by-nc/4.0/ Este artigo é de acesso aberto distribuído sob os termos da Licença Creative Commons (CC BY-NC).

Esta licença permite que outros remixem, adaptem e criem a partir do seu trabalho para fins não comerciais. Embora os novos trabalhos tenham de lhe atribuir o devido crédito e não possam ser usados para fins comerciais, os usuários não têm de licenciar esses trabalhos derivados sob os mesmos termos. 